\title{
Correction to: CMOS Image Sensor with Tunable Conversion Gain for Improved Performance
}

\section{Gaurav Musalgaonkar ${ }^{1}$ (D) Raghvendra Sahai Saxena $^{1}$}

Published online: 27 May 2019

(c) Springer Science+Business Media, LLC, part of Springer Nature 2019

\section{Correction to: Sensing and Imaging (2019) 20:16 https://doi.org/10.1007/s11220-019-0237-z}

The original version of this article unfortunately contained a mistake. Figure 1 was partly missing at the bottom in the pdf and xml versions of the article. The corrected figure is given below. The original article was corrected.

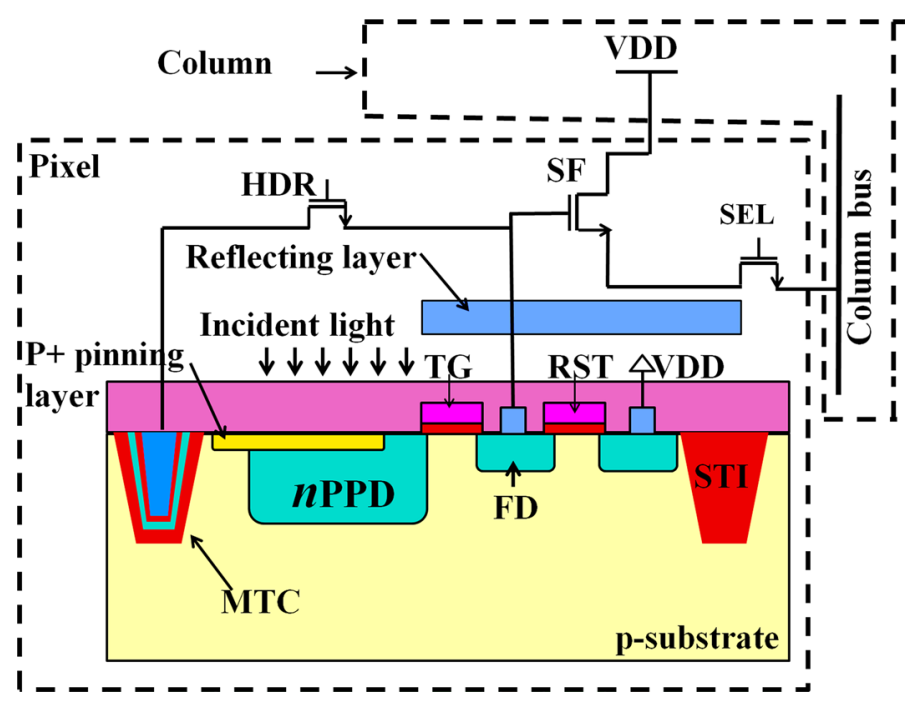

Fig. 1 Proposed structure of 5T Pixel with in-built trench capacitor

The original article can be found online at https://doi.org/10.1007/s11220-019-0237-z.

Gaurav Musalgaonkar

gaurav.musalgaonkar7@gmail.com

1 Solid State Physics Laboratory, DRDO, New Delhi 110054, India 
Publisher's Note Springer Nature remains neutral with regard to jurisdictional claims in published maps and institutional affiliations. 